Revista Española de Antropología Americana ISSN: 0556-6533

https://doi.org/10.5209/reaa.66521

\title{
La iconografía de los queros del Museo de La Plata. Primeras aproximaciones interpretativas
}

\author{
María Cecilia Paez ${ }^{1}$, Bianca Minichelli², Guillermo German Joosten ${ }^{3}$ e Inés \\ Forgnone ${ }^{4}$
}

Recibido: 12 de octubre de 2017 / Aceptado: 26 de junio de 2018

Resumen. Los vasos de madera del período Colonial andino destacan por su simbolismo y policromía, reuniendo elementos iconográficos propios de la idiosincrasia prehispánica americana en una estructura del diseño que encuentra similitudes con el barroco europeo. Este entramado de signos refleja la compleja realidad de las elites incaicas -con quienes se vincula la utilización de los queros-, en el nuevo contexto político y social impuesto por el orden colonial. En este trabajo presentamos el análisis de 10 vasos de madera procedentes del Cusco, depositados en el Museo de La Plata (Argentina). Proponemos que la gráfica de estas piezas constituye una forma alternativa a la oralidad para la reproducción de la memoria colectiva y el fortalecimiento de las identidades indígenas.

Palabras clave: Andes; período Colonial, elites incaicas, memoria.

\section{[en] The Iconography of the Keros of the Museum of La Plata. First Interpretative Approaches}

\begin{abstract}
The wooden vases of the Andean Colonial Period stand out for their symbolism and polychromy, gathering iconographic elements typical of the American pre-Hispanic idiosyncrasy in a design structure that finds similarities with the European Baroque. This network of signs reflects the complex reality of the Inca elites, with whom the use of keros is linked, in the new political and social context imposed by the Colonial order. In this work we present the analysis of 10 wooden vases coming from Cusco, deposited in the Museum of La Plata (Argentina). We propose that its iconography constitute an alternative form to the orality for the reproduction of the collective memory and the strengthening of the indigenous identities.
\end{abstract}

Keywords: Andes; Colonial Period; Inca elites; memory.

Sumario: 1. Introducción. 2. Metodología. 3. Resultados. 4. A modo de cierre. 5. Referencias.

Cómo citar: Paez, María Cecilia, Bianca Minichelli, Guillermo German Joosten e Inés Forgnone. 2019. «La iconografía de los queros del Museo de La Plata. Primeras aproximaciones interpretativas». Revista Española de Antropología Americana 49: 73-85.

1 CONICET- División Arqueología. Museo de La Plata. Facultad de Ciencias Naturales y Museo. Universidad Nacional de La Plata, Argentina. ceciliapaez@gmail.com.

2 Facultad de Ciencias Naturales y Museo. Universidad Nacional de La Plata, Argentina. biancaminichelli2012@ gmail.com.

3 CONICET- División Antropología. Museo de La Plata. Facultad de Ciencias Naturales y Museo. Universidad Nacional de La Plata, Argentina. joosten.g7@gmail.com.

${ }^{4}$ Facultad de Ciencias Naturales y Museo. Universidad Nacional de La Plata, Argentina. inesfor@hotmail.com. 


\section{Introducción}

Los queros (del quechua: qiru = madera) son vasos de madera muy extendidos durante el período de expansión incaica, aunque su origen se remonta a tiempos prehispánicos. Los queros prehispánicos presentan forma troncocónica, grabado sobre madera y motivos geométricos, contrastando significativamente con la variedad de formas, la pintura policromática y las escenas que definen los queros del período Colonial. Si bien algunos autores sugieren que la presencia de laca en los vasos es una técnica adoptada en los momentos finales del Tawantinsuyu (Ramos 2006; Kuon 2011), la estructura del diseño y la simbología de los vasos postconquista no permiten dudas acerca del cambio ideológico que representan. Desde el punto de vista morfológico, las vasijas más comunes son aquellas cuyo diámetro a la altura de la boca supera al de la base. No obstante, hay una variedad mayor a la que no nos referiremos por cuestiones de espacio y porque han sido desarrolladas in extenso por especialistas en el tema (Rowe 1961; Liebscher 1986; Flores et al. 1998; Cummins 2002; Ramos 2006). Una de ellas presenta similitudes con la copa europea y el cáliz cristiano, lo que ha motivado que se interprete la aparición de esta forma en vinculación con los regalos que los españoles dieron a los jerarcas incaicos en ocasión de su llegada al territorio americano (Ramos 2006).

Más allá de las formas, tamaños y decoraciones, su interpretación funcional guarda relación con los convites ceremoniales y el brindis como práctica política y social, que incluía agradecimientos, peticiones, negociaciones o cualquier otra forma de relación inter o intra-étnica. Diferentes contextos dan cuenta de su uso: espacios políticos de interacción entre españoles e incas, negociaciones entre jerarquías nativas o vínculos de amistad entre la población local, celebraciones calendáricas en torno a la siembra o la cosecha, o en ocasión al culto a las huacas o los mallquis, tal como se desprende del análisis de los dibujos de Guaman Poma de Ayala (2005 [1615]; Alonso 1990). Desde el período incaico, habrían circulado entre los miembros de la elite, situación que se habría reproducido luego de la conquista, cargado de nuevos significados como producto de la nueva situación de los sectores de elite nativos.

Los cambios en la sociedad indígena tras la conquista española significaron un reposicionamiento de los sectores de privilegio de la nobleza indígena en el nuevo contexto de dominación colonial. Algunos autores sostienen que el despliegue visual de los queros coloniales, con su abundante simbología nativa, habría funcionado como un instrumento de legitimación de las jerarquías incaicas ante la pérdida de poder en el siglo XVI (Ziólkowski 2009). Al respecto, estudios etnohistóricos mencionan que la utilización de los emblemas de poder por parte de las élites habría sido una forma de legitimar su posición no sólo frente a la mirada europea, sino también hacia dentro de sus propios ayllus. Se destacan dos aspectos significativos, a saber: la utilización de símbolos de la cultura del colonizador, que se terminan incorporando dentro de la idiosincrasia cotidiana, y la utilización y referencia a los símbolos de poder andinos que definieron su posición e identidad en los momentos previos (Bunster 2001). Otras interpretaciones se enfocan hacia el potencial de la representación pictórica de los queros para mantener viva la memoria social, funcionando como un factor de cohesión frente al nuevo contexto de desestructuración (Lizárraga 2009; Martínez Cereceda et al. 2014, 2016). De esta manera, las reconfiguraciones y transformaciones decorativas relacionadas con la policromía, los espacios cargados propios del barroco europeo y la utilización de nuevos significantes visuales repre- 
sentan una forma de disimulo frente a la vigilancia del orden colonial (Lizárraga 2009, 2015).

Partiendo de este marco, en este trabajo nos proponemos explorar las particularidades decorativas de un conjunto de piezas procedentes del Museo de La Plata (La Plata, Buenos Aires). Este conjunto forma parte de una muestra más amplia, que incluye otros museos de Argentina, que están actualmente bajo estudio. Su análisis pretende aportar a la comprensión de las expresiones que un segmento de la sociedad indígena habría dejado plasmada en estas piezas, a la luz de las nuevas circunstancias creadas por el orden colonial.

\section{Metodología}

La investigación estuvo enfocada en una muestra de queros $(\mathrm{n}=10)$ perteneciente a la colección Muñiz Barreto (División Arqueología, Museo de La Plata), procedente de Cusco y asignada cronológicamente al período Colonial. Se trabajó a partir de un registro escrito y fotográfico. El primero de ellos requirió la confección de una ficha que contempla los siguientes datos: asignación, procedencia y localización de las piezas, variables morfométricas, técnicas de acabado de superficie, diseños iconográficos, rastros de uso, presencia de marcas y estado de conservación de las piezas (Figura 1). Las variables morfométricas fueron tomadas de Ziólkowski (2000).

Para los fines del análisis se consideraron dos ejes espaciales dentro de los queros, uno horizontal y otro vertical. Verticalmente, se pueden distinguir «bandas» que rodean al vaso y presentan composiciones diferentes. Horizontalmente, se puede asignar a cada banda una lectura, que va a ser distinta dependiendo del tipo de representación que se esté observando (Martínez Cereceda 1986). Aunque no existe un indicio de inicio o fin, pues se caracterizan por una continuidad, para los fines del análisis se asignó un punto arbitrario de inicio, realizando la lectura de izquierda a derecha.

\section{Resultados}

La cantidad de bandas presentes en los queros analizados es variable, pero mayormente se encuentran en números de dos o tres. Del mismo modo, las representaciones expresadas en cada una suelen variar según la cantidad del total de bandas. Cuando los queros poseen tres, la superior lleva representaciones humanas, la intermedia una sucesión continua o discontinua de tocapus y la inferior representaciones florales. En cambio, cuando el quero posee dos bandas, la superior se compone de tocapus y la inferior de representaciones florales. Existen excepciones dentro de la muestra, por ejemplo, en uno de los casos investigados (Figura 2) la decoración de la pieza está dividida, en sentido vertical, en dos mitades, una de ellas con representaciones de flores, en tanto en la otra se disponen en bandas, escenas, flores y tocapus. También se identificaron vasos que presentan una sola banda de representación (Figuras 3 y 4) que pueden, o bien concentrar diseños florales en todo el espacio, o bien incluir flores, tocapus y animales en un diseño combinado (Cuadro 1). Además, en ellos se observan diseños de festones y triángulos por fuera del marco que concentra la composición central. No es clara su asignación a bandas independientes, dado que 


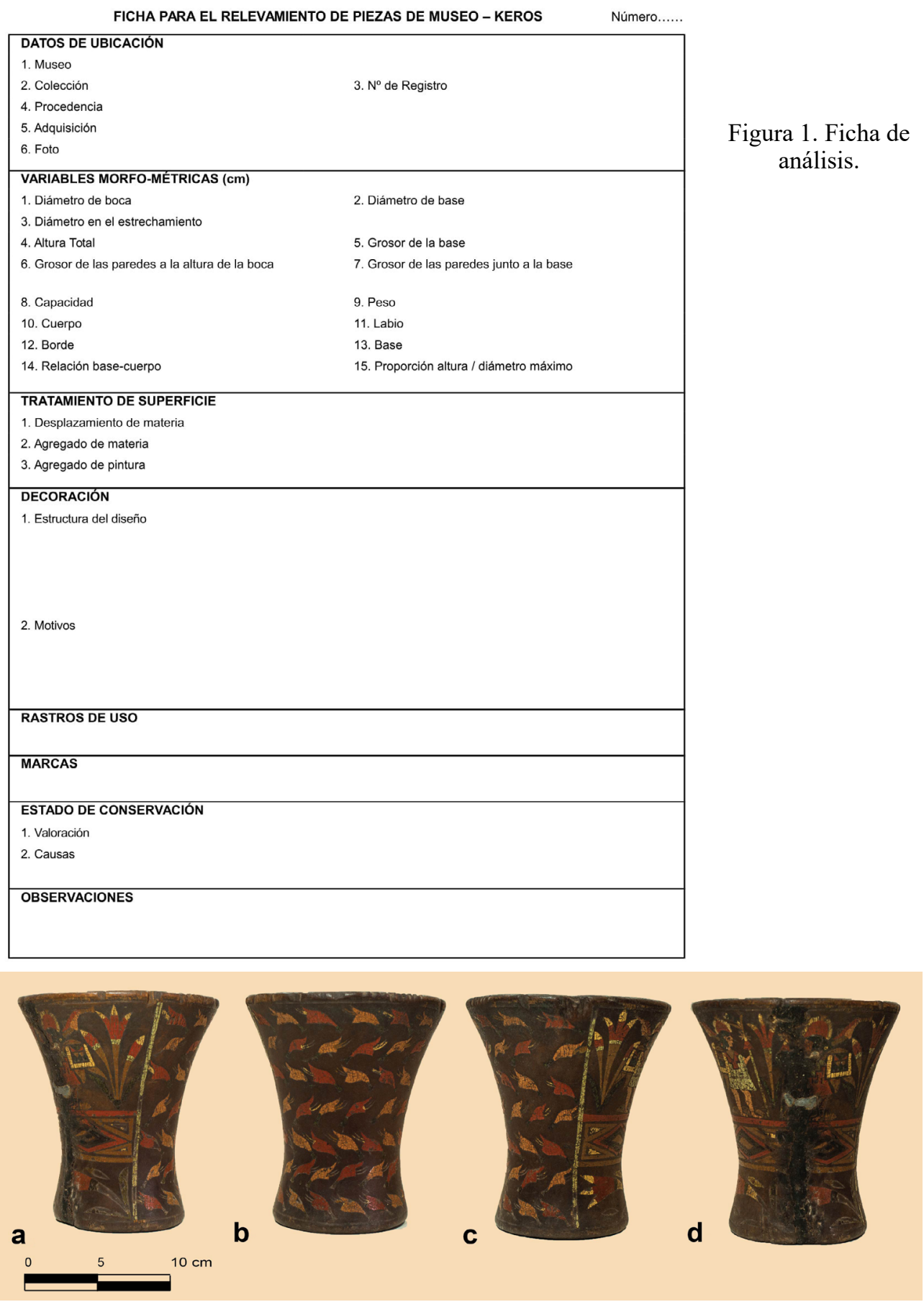

Figura 2. Quero 1449: a) separación vertical en dos mitades (disposición particular de este ejemplar); b) patrón repetitivo de flores ñucchu, alternando entre colores rojos y naranjas; c) idem a; d) tres bandas en disposición vertical: la primera una escena real donde se enfrentan dos individuos, acompañados de tres flores (especie no determinada). La segunda una banda de tocapus y la tercera una banda con representaciones florales. 
si así fuera, faltaría el característico recuadro que sirve de contención a las representaciones. No obstante, no se descarta que una mayor profundidad en los análisis nos lleve a modificar estas interpretaciones.

Cuadro 1. Distribución de las representaciones

de acuerdo a la estructuración del espacio en el quero

\begin{tabular}{|c|c|c|c|c|c|c|}
\hline \multirow{2}{*}{$\begin{array}{l}N^{\circ} \text { de bandas/ } \\
\text { queros }\end{array}$} & \multicolumn{3}{|c|}{3 bandas } & \multicolumn{2}{|c|}{2 bandas } & \multirow{2}{*}{$\begin{array}{c}1 \text { banda } \\
\text { Única }\end{array}$} \\
\hline & Superior & Media & Inferior & Superior & Inferior & \\
\hline 1446 & Escena & Tocapus & Flores & & & \\
\hline 1447 & Escena & Tocapus & Flores & & & \\
\hline 1448 & Escena & Tocapus & Flores & & & \\
\hline 1449 & Escena & Tocapus & Flores & & & \\
\hline 1451 & & & & Tocapus & Flores & \\
\hline 1453 & & & & & & Flores \\
\hline 4275 & & & & & & $\begin{array}{c}\text { Tocapus/ } \\
\text { Flores/ } \\
\text { Animales }\end{array}$ \\
\hline 4276 & & & & Tocapus & Flores & \\
\hline $\mathrm{s} / \mathrm{n}$ & Escena & Tocapus & Flores & & & \\
\hline
\end{tabular}
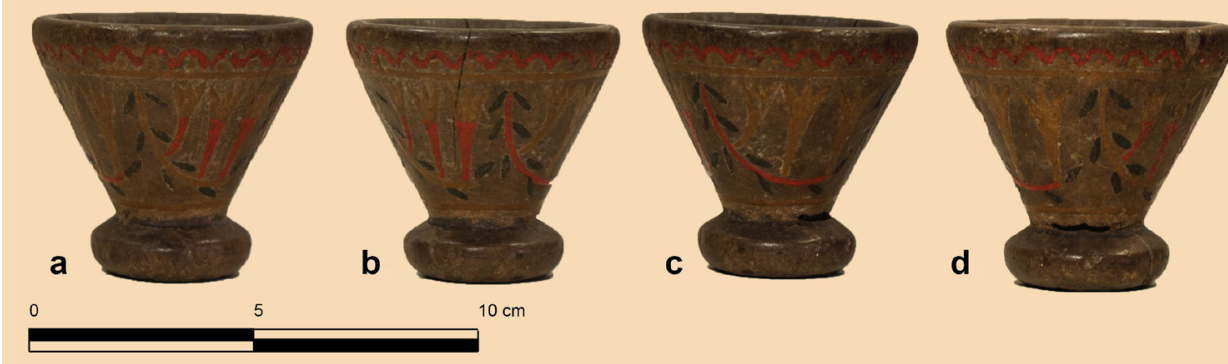

Figura 3. Quero 1453b compuesto por una banda única donde se representa una secuencia de ramas de cantuta: a y b) la corola presenta dos colores distintos; c y d) la corola presenta un único color.

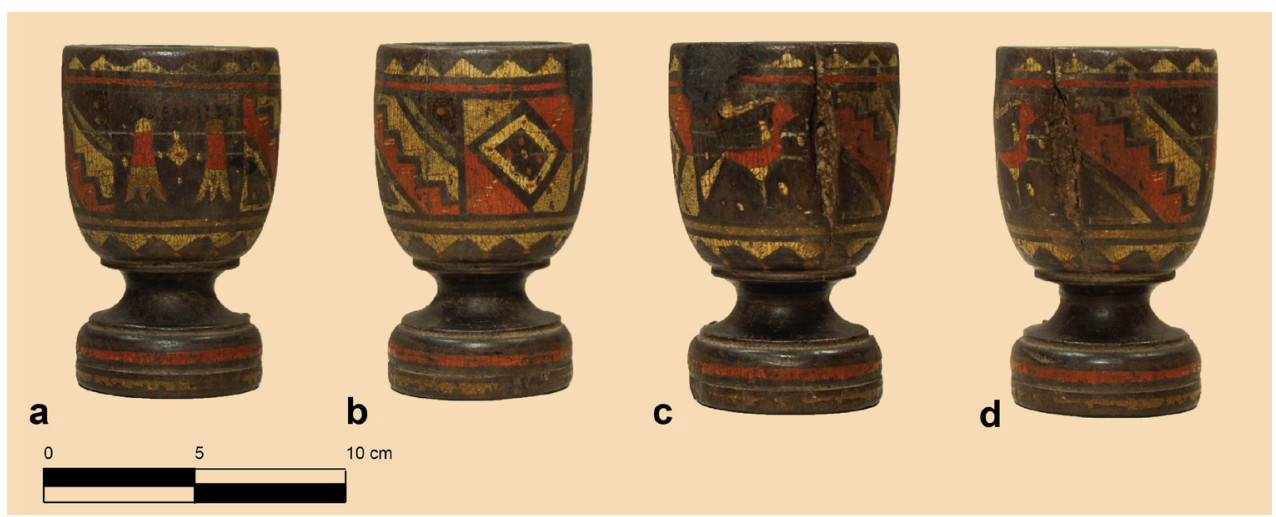

Figura 4. Quero 4275 con base pedestal: compuesto por una única banda de tocapus interrumpidos (b y d) por flores de cantuta (a) y un hoatzín (c). En las partes superior e inferior se observan formas geométricas a modo de guarda. 


\subsection{Tocapus}

A partir de la estructura del diseño, nos centraremos inicialmente en la descripción de los tocapus, fijándonos en su ubicación y características dentro del quero. Uno de los aspectos que merece atención es la variabilidad de las representaciones en lo que respecta al número, disposición en el quero, tipo de representaciones en cada uno y combinaciones posibles. Ziólkowski (2009) hace dos apreciaciones en referencia a una extensa muestra de queros analizados. En primer lugar, que hay una estrecha relación entre la complejidad compositiva y el número de tocapus, esperándose mayor número de estos últimos en aquellos vasos con escenas complejas, de carácter histórico. En segundo lugar, que hay un intercambio icónico entre las escenas y los tocapus, relacionado en función de la transmisión de un mensaje.

En los diseños de los vasos relevados se observa un uso recurrente de líneas rectas y puntos que forman figuras geométricas como rectángulos, escalones, cruces o aspas y cuadrados y, en menor frecuencia, aparecen líneas curvas. En algunos casos, también se hallan representados los escudos de los emperadores Inca, aunque en la presente muestra no se han encontrado (Gentile 2010). Los colores utilizados son variados aunque en su mayoría se observa el rojo, verde, amarillo, naranja, marrón y blanco.

Su posición en el quero varía de acuerdo a la cantidad de bandas que lo compongan. En aquellos que tienen 3, los tocapus están en la del medio y su tamaño es más pequeño en relación a la banda superior e inferior (ver Figura 2). En cambio, cuando sólo hay dos (Figuras 5 y 6), los tocapus se encuentran en la banda superior y su tamaño es igual a la inferior, ocupando la mitad del quero. Las bandas suelen estar delimitadas por líneas de colores. Asimismo, los tocapus dentro de la banda están separados por líneas o por el límite mismo de cada uno. En aquellas bandas en las que hay repetición, éstos pueden ser exactos o presentar diferencias menores.

\subsection{Flores}

En relación a las flores, la bibliografía remite a diferentes especies representadas en los vasos. Un aspecto a remarcar es la dificultad en la identificación de las especies dibujadas, sobre las que existe literatura específica (Yacovleff y Herrera 1935; Vargas 1947; Mulvany 2004). En la muestra que analizamos, la flora acontece con mayor asiduidad en la banda inferior del vaso y suele disponerse en secuencias repetitivas. En un mismo quero puede encontrarse una sola especie o a veces dos. Cuando aparecen en la banda superior, están intercaladas con otros elementos que componen las escenas. Hay al menos tres especies representadas en la muestra, de las cuales sólo se pudieron determinar con certeza dos.

Cantuta o Flor Sagrada del Inca (Cantua buxifolia): flor nacional del Perú (ver Figura 3). Crece de manera silvestre o cultivada, principalmente en las zonas andinas de Bolivia y Perú entre los 1200 y $3800 \mathrm{msnm}$. Aparece representada en el quero s/n (Figura 7), acompañando una escena real. La corola está formada por pétalos fusionados de forma tubular y de colores muy llamativos, generalmente blanco, amarillo, rosado y rojo intenso. Se disponen de forma péndula en racimos como el que está llevando la colla en una de las escenas (Figura 7c) y, al igual que en la planta viva, conviven flores abiertas y pimpollos en una misma rama. También se observan dos ejemplares en los espacios entre arco iris, los cuales sólo presentan pimpollos pero no flores abiertas (Figura $7 \mathrm{~b}$ y d). 

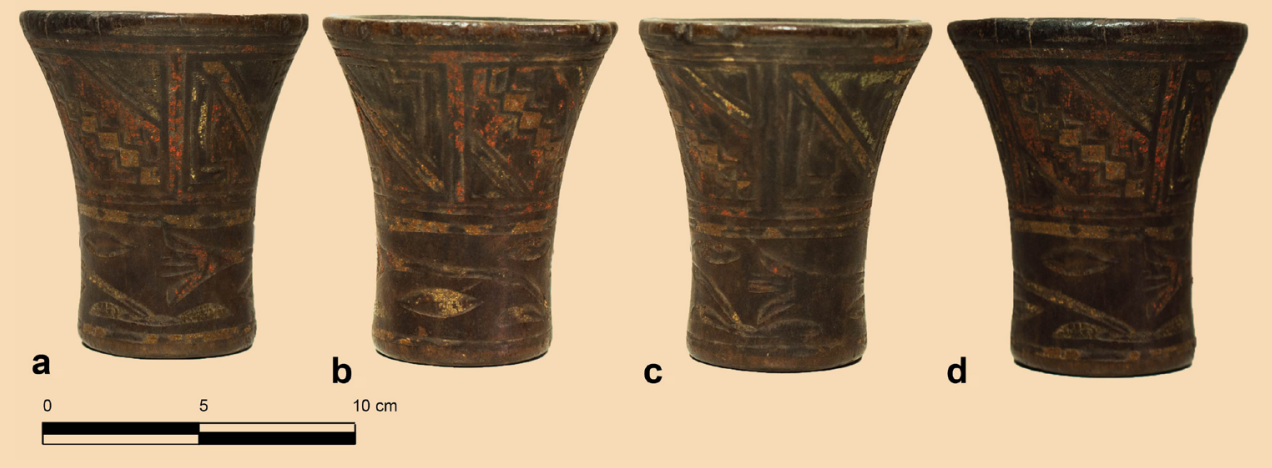

Figura 5. Quero 1451: compuesto por una banda superior con cuatro tocapus y una inferior con flores de ñucchu y la especie indeterminada. Los cuatro tocapus se presentan en forma de pares repetidos.

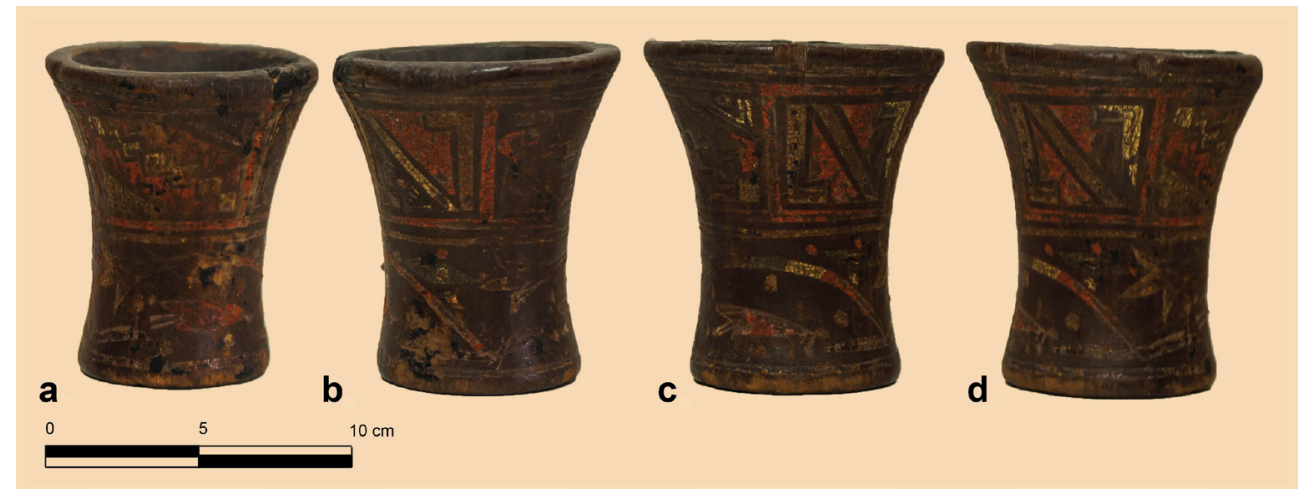

Figura 6. Quero 4276: esencialmente igual al Quero 1451 (Figura 5), pero sin flores nucchu. Los tocapus presentan la misma repetición de pares.

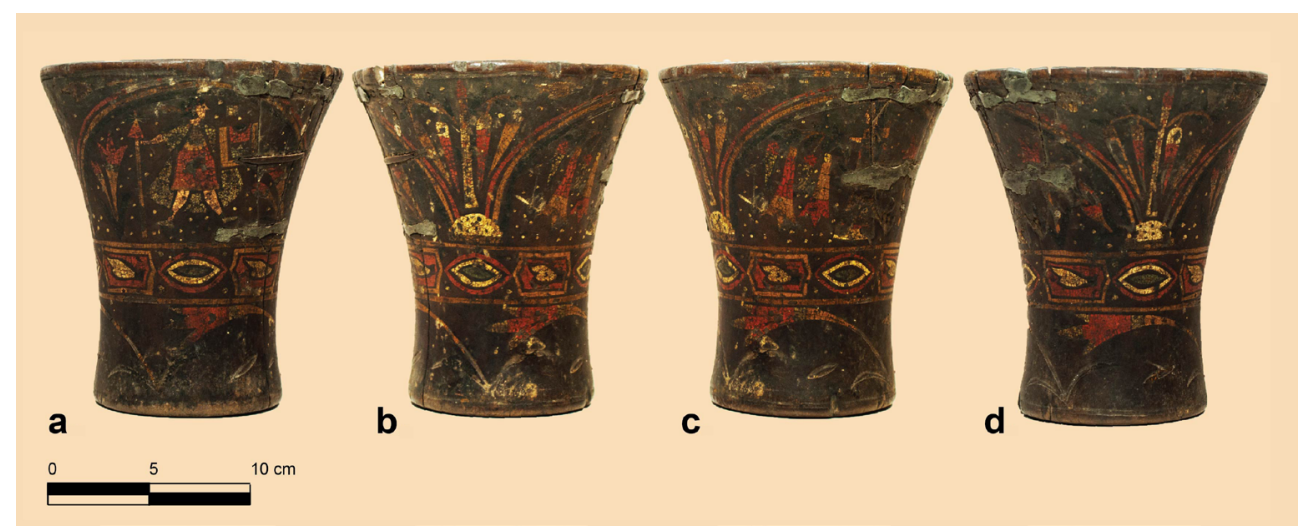

Figura 7. Quero s/n de tres bandas: en la banda superior se observa un jerarca Inca (a) y una Colla que porta una rama de cantutas (c), separados por dos arcoíris, entre los que se encuentran ramos de flores cantutas cerradas (b y d). En la banda intermedia una secuencia de tocapus en las que aparecen flores ñucchu y en la inferior se encuentra la flor indeterminada. 


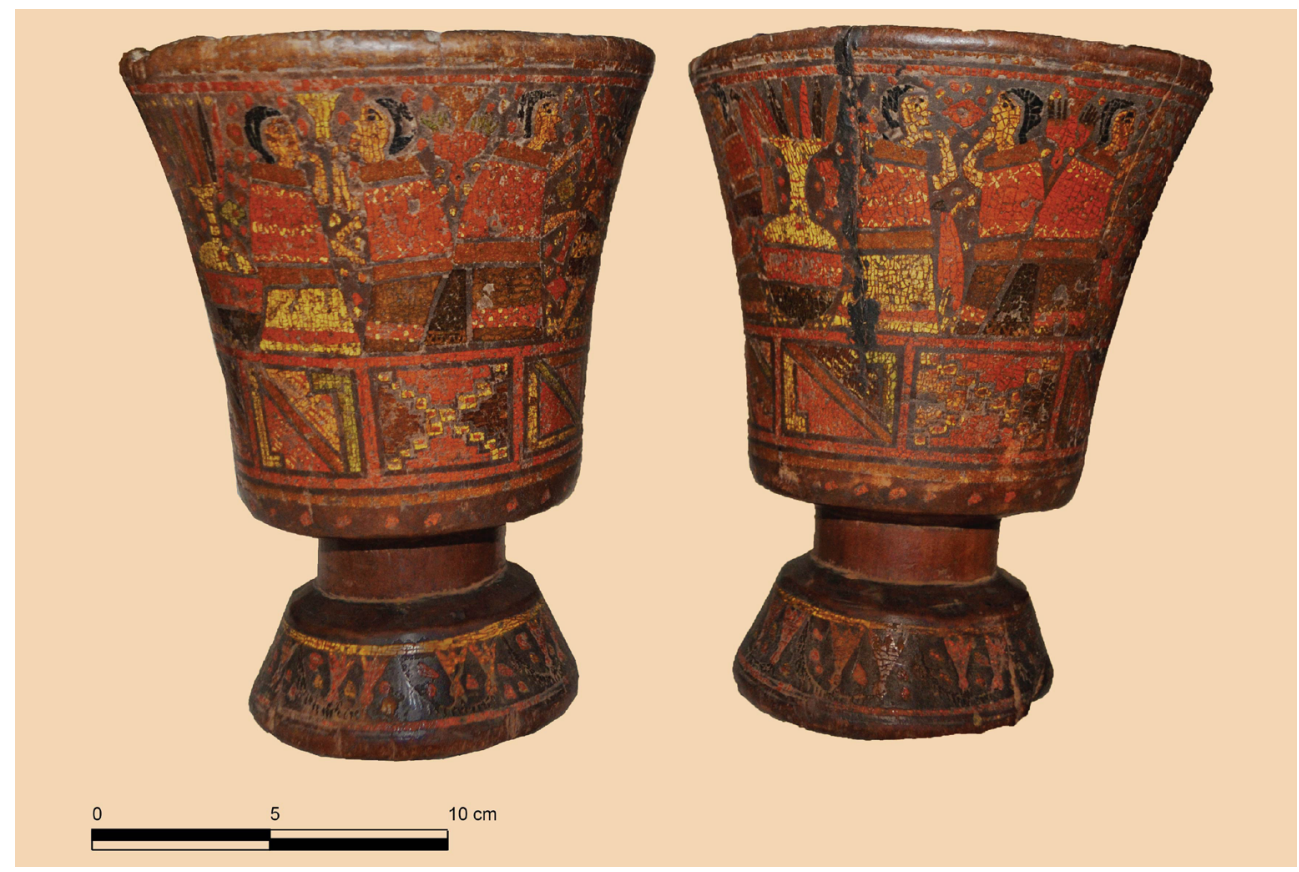

Figura 8. Queros mellizos con base pedestal 1446 y 1447.

Flor ñucchu (Salvia opositiflora): se encuentra rellenando las representaciones de escenas en los queros mellizos 1446 y 1447 (Figura 8) y s/n (ver Figura 7), formando paneles enteros en el quero 1449 (ver Figura 2) y acompañando a los motivos florales de los campos inferiores. Presenta el cáliz corto de color verde y la corola de forma tubular y bilabiada, de la cual sobresalen dos estambres. Los colores varían desde el rosado al rojo intenso. Florece en la estación de lluvias y crece entre 2100 y $3600 \mathrm{msnm}$.

\subsection{Aves}

La representación de aves en los queros es un elemento de importancia en nuestra muestra, así como en las de otros trabajos y siempre se encuentran en íntima relación con el conjunto de la escena. Para la sociedad incaica, las mismas presentan distintos significados o interpretaciones, según su especie. Las variedades identificadas en este trabajo se basan en semejanzas morfológicas y distribución cercana al Cuzco (Narozky e Yzurieta 2010), lo que a su vez estuvo apoyado por la mención de otros autores, como Capriles y Flores (1999). Se pudieron determinar con mayor o menor grado de certeza las tres especies de aves presentes en la muestra.

Caracara o carancho andino (Phalcoboenus megalopterus): aparece representado en el quero 1448 (Figura 10). Se trata de un ave negra, incluso en el pecho, de tamaño grande. Posee una cola larga, de igual longitud que el resto del cuerpo. Los ápices de las plumas alares y caudales son de color blanco, así como el vientre, patas y, posiblemente, la rabadilla. Uno de los ejemplares del quero no presenta la rabadilla blanca, pero sí el margen lateral de la cola. Posee pico corto, recto y rojo. El área 


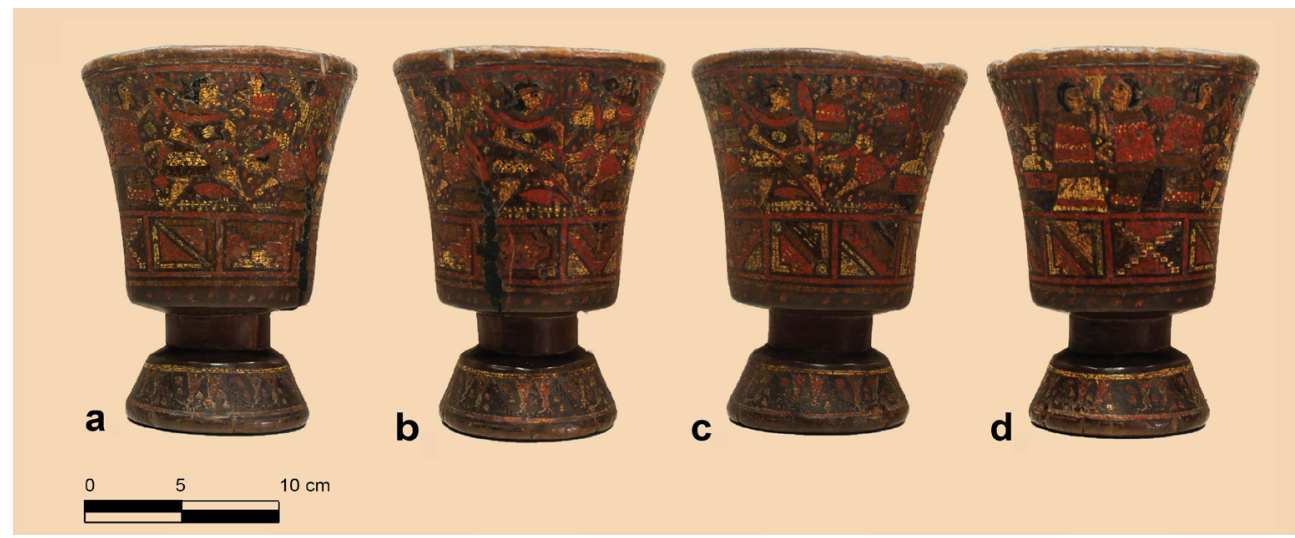

Figura 9. Quero 1446: a-d) banda superior con una compleja trama de escenas acompañadas por un picaflor gigante (d) y flores ñucchu. En la banda intermedia se presenta una secuencia de tocapus y la inferior -que se encuentra en la base pedestal- muestra una secuencia de ramas de cantuta que abren hacia arriba.

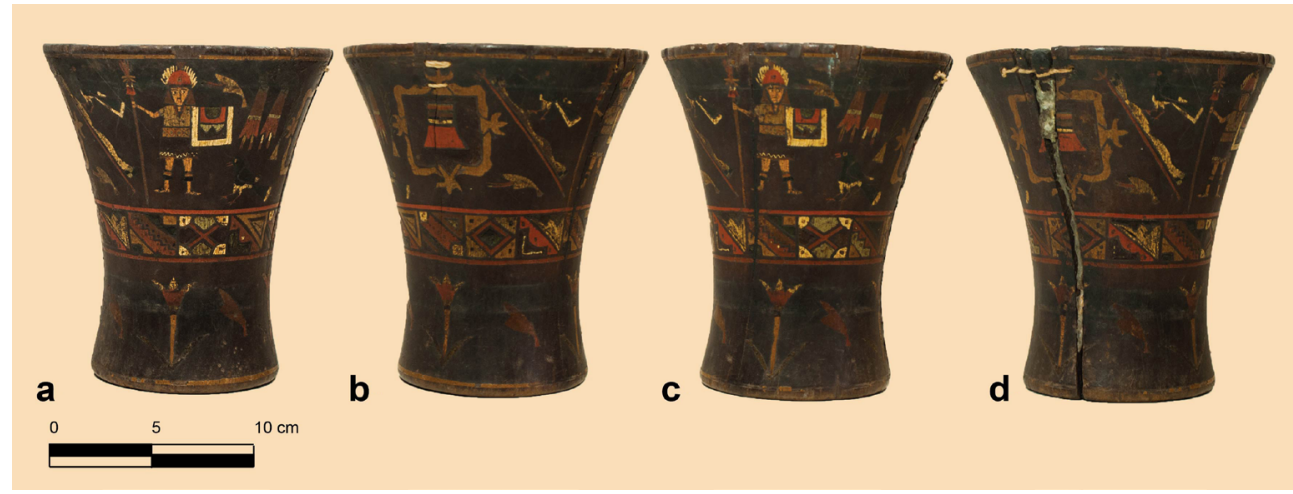

Figura 10. Quero 1448 compuesto por tres bandas: en la banda superior se observa un jerarca acompañado por dos caranchos andinos, una rama de cantuta y un escudo. En la banda intermedia una secuencia de tocapus y en la inferior se encuentra la misma flor indeterminada que en la Figura 2 junto con flores ñucchu.

ocular es anaranjada y las patas son de color amarillo y sin plumas. Según Ziólkowski (2009), las plumas de esta ave eran utilizadas en la indumentaria inca y, además, representaban una insignia para los jerarcas. En el quero 1448, se encuentran representados dos caranchos, que se encuentran a ambos lados de un jerarca Inca. La semejanza morfológica y de color entre el dibujo y la especie es la mayor de las tres $\mathrm{y}$, por consiguiente, también lo es la certeza de la determinación.

Shansho u hoatzín (Opisthocomus hoazin): esta ave se observa en el quero 4275 en la única banda que compone el quero, interrumpiendo una secuencia de tocapus (ver Figura 4). Es un ave anaranjada, de pico corto y terminado en punta. Posee un gran copete o penacho que apunta hacia atrás. El ala es de color verde con base blanca y líneas naranjas generando un patrón cuadriculado. La cola es larga y blanca. Las patas son largas y verdes, con la base emplumada blanca. Esta especie no se encuentra normalmente en el Cuzco, pero sí a menos de 100 kilómetros en la Amazonía peruana. 
Picaflor gigante (Patagona gigas): esta ave se encuentra en los queros mellizos 1446 y 1447 (ver Figura 8). Se localiza en la banda superior del quero formando parte de una escena ritual de cultivo y en posición de vuelo. Es de color rojizo, excepto por la cola marrón y las plumas terminales oscuras. Según la distribución de colores, lo que se observa representado en los queros es el vientre del ave. Su pico es largo, angosto y puntiagudo. Es el representante de mayor tamaño de su familia y se encuentra en las alturas (zona andina) solo durante la primavera y el verano. Además, es interesante resaltar que esta ave se alimenta del néctar de todas las especies de flores que se encuentran representadas en los queros. Las mismas presentan una morfología tubular, disposición péndula y colores rojizos, producto de una convergencia evolutiva a ser polinizadas por picaflores. En los queros mellizos, la banda inferior tiene representadas flores que apuntan hacia arriba, a la vez que en la banda superior el picaflor apunta hacia ellas.

\subsection{Escenas}

En el conjunto de los queros analizados se identificaron 5 ejemplares con representación de escenas y dos de ellos son queros mellizos. Se identificaron distintos tipos de escenas:

Escena festivo-ritual: presente en los queros mellizos y, sin duda, vinculada al cultivo (ver Figura 9a). Hay tres figuras de un par masculino-femenino, formado por el hombre con un palo cavador y la mujer agachada esparciendo semillas con un saco en su espalda. Acompañan a estas otras tres figuras de pares: hombre-llama y dos pares mujer-mujer. En el primer caso, el hombre está arreando una llama con lo que podría ser un instrumento musical en su boca (ver Figura 9b). Los pares femeninos reflejan el brindis entre dos mujeres enfrentadas, cada una con un quero en la mano (ver Figura 9c), y dos mujeres hablando también en posición enfrentada (ver Figura 9d). Finalmente, hay otra mujer con un quero en cada mano, que se ubica por detrás de uno de los hombres con palo cavador que componen las tres escenas repetidas (ver Figura 9a).

En la misma banda, se observa un aríbalo de gran tamaño, flores de ñucchu y un picaflor gigante. La presencia de esta ave en la representación coincidiría con los meses de primavera y verano, que es cuando se encuentra en las alturas. Esto guarda concordancia con las fechas estimadas para la siembra. La presencia de elementos musicales, vasos y aríbalos podría sugerir la representación de rituales de carácter agrícola. Martínez de la Torre (1993: 21) hace mención de dos de ellos, que se podrían corresponder con las ilustraciones de los queros que analiza. Uno de ellos es el Cusquie Raimi, en la cual se pedía por la prosperidad de la cosecha. La otra festividad, que aparece relatada en los dibujos de Guaman Poma (2005 [1615]) corresponde al mes de diciembre y está relacionada con el crecimiento del maíz, principal cultivo de la región. La vinculación con los camélidos también abona a la idea de crianza con la que se identifica la relación entre los hombres y su entorno natural en tiempos prehispánicos y aún en la contemporaneidad de la vida en los Andes (Van Kessel y Condori Cruz 1992).

Escenas reales: la primera está en el quero 1448 (ver Figura 10). Se trata de la figura de un inca con su atuendo particular y su chucu, portando en una mano un escudo similar al que se asigna a la dinastía de Amaro Topa Inca y en la otra un cetro. De acuerdo a Gentile (2010), la presencia de estos escudos se asocia a las ce- 
remonias agrícolas dado el impulso que este jerarca le dio a las técnicas de siembra. La representación se completa con las figuras de dos caranchos andinos (ave que aparece asociada a las jerarquías inca), flores ñucchu, otras flores no identificadas que parecen pertenecer a una misma especie y una insignia que podría estar asociada a una panaca real.

La segunda escena real aparece en el quero 1449 (ver Figura 2d). Se trata de dos incas enfrentados, de perfil, con unku, chucu, un cetro en una mano y un escudo en la otra. Están rodeados por tres flores indeterminadas de gran tamaño y dos flores ñucchu en la parte superior. La mitad posterior del quero presenta todo un panel de flores ñucchu dispuestas en filas alternando su dirección.

La tercera escena real alude a la pareja real, el Inca y la Colla, en una pieza sin número (ver Figura 7). Contiene dos arcos iris; debajo de uno hay un Inca y del otro una Colla. El primero está dotado de escudo, capa y lanza; en tanto la mujer sostiene un ramillete de flores de cantuta. Entre ambos arco iris hay dos plantas de cantuta y algunas flores ñucchu. Debajo de cada arco iris, acompañando a los personajes, hay otras flores que se repiten en la mitad inferior del quero, fuera de la escena.

\section{A modo de cierre}

El análisis de la muestra de queros coloniales depositados en el Museo de La Plata ha permitido una primera aproximación a los aspectos relacionados con el simbolismo representado en estas piezas. En este sentido, es preciso remarcar la dificultad para identificar las especies animales y vegetales representadas, lo que implica que el repertorio natural reproducido pudiera ser mucho más amplio del que efectivamente mencionamos.

En la mayor parte de los elementos representados, hay una referencia directa a aspectos de la cosmovisión propia del mundo nativo. Las menciones a la crianza de animales y plantas, a la vinculación de esas prácticas con contextos festivos/ rituales a través de la música o los brindis, a elementos del mundo natural y la ponderación de la figura real provista de sus atavíos, son algunos de los elementos que nos llevan a sostener que la memoria prehispánica seguía muy presente en la época postconquista. La forma en que ella se mantiene en el contexto de desestructuración que significó el nuevo orden para las poblaciones americanas, representa uno de los desafíos a futuro. Es posible que la narrativa de los queros haya pretendido un rol activo hacia el interior de los grupos, al reafirmar cuestiones vinculadas a la identidad en la diferenciación de un otro occidental, presente en el mismo espacio social. También se puede proponer que los grupos nativos habrían encontrado en la gráfica de los vasos una forma alternativa a la oralidad para la reproducción de la memoria colectiva, lo que constituye una forma de resistencia frente a la nueva sociedad y la nueva historia impuesta por Europa.

La breve descripción que realizamos en este trabajo pretende valorar la riqueza de este registro para abordar las características de las relaciones sociales durante la Colonia, atravesadas por el poder, la imposición y la resistencia. Los resultados alcanzados orientan una dirección futura en la cual se trabajará a partir de la ampliación de la muestra y la profundización de los análisis. 


\section{Referencias}

Alonso Sagaseta de Ilurdoz, Alicia. 1990. «El kero: vaso ritual de los incas». Espacio, Tiempo y Forma. Serie VII, Historia del Arte 3: 11-31.

Bunster, Cora. 2001. «Las autoridades indígenas y los símbolos de prestigio». Andes 12 [en linea]. http://oai.redalyc.org/articulo.oa?id=12701205.

Capriles, José María y Eliana I. Flores. 1999. «Representación Iconográfica de Flora y Fauna en Kerus Incas». Revista de la Fundación Cultural del Banco Central de Bolivia 6: 7-19.

Cummins, Thomas. 2002. Toasts with the Inca. Andean Abstraction and Colonial lmages on Quero Vessels. Ann Arbor: University of Michigan Press.

Flores Ochoa, Jorge, Elizabeth Kuon Arce y Roberto Samanez Argumedo.1998. Queros. Arte inka en vasos ceremoniales. Lima: Banco de Crédito del Perú.

Gentile, Margarita E. 2010. «Tocapu: unidad de sentido en el lenguaje gráfico andino». Espéculo. Revista de Estudios Literarios 45 (julio-octubre 2010). https://webs.ucm.es/info/ especulo/numero45/tocapu.html.

Guaman Poma de Ayala, Felipe. 2005 [1615]. Nueva coronica y buen gobierno. Lima: Fondo de Cultura Económica.

Kuon Arce, Elizabeth. 2011. «Los qeros en el marco del barroco andino», en Memoria del I Encuentro Internacional sobre Barroco, pp. 211-220. Pamplona: Fundación Visión Cultural, Servicio de Publicaciones de la Universidad de Navarra. http://dadun.unav.edu/ bitstream/10171/17970/1/19_Koun\%20Arce.pdf.

Liebscher, Verena. 1986. La iconografía de los queros. Lima: G. Herrera Editores.

Lizárraga Ibáñez, Manuel Antonio. 2009. «Las élites andinas coloniales y la materialización de sus memorias particulares en los 'queros de la transición' (vasos de madera del siglo XVI)». Boletín del Museo Chileno de Arte Precolombino 14 (1): 37-53.

- 2015. «Los queros y la imaginería andina colonial». Arqueología y Sociedad 29: 365-391.

Martínez Cereceda, José Luis. 1986. «El «Personaje sentado» en los Keru: hacia una identificación de los kuraka andinos». Boletín del Museo Chileno de Arte Precolombino 1: 101-124.

Martínez Cereceda, José Luis, Carla Díaz, Constanza Tocornal y Verónica Arévalo. 2014. «Comparando las crónicas y los textos visuales andinos. Elementos para un análisis». Chungará 46 (1): 91-113.

Martínez Cereceda, José Luis, Carla Díaz, Constanza Tocornal, Gabriela Acuña y Luz María Narbona. 2016. «Qeros y discursos visuales en la construcción de la nueva sociedad colonial andina». Anuario de Estudios Americanos 73 (1): 15-43.

Martínez de la Torre, Cruz. 1993. «La tradición musical andina en vasos de madera incas». Espacio, Tiempo y Forma, Serie VII, Historia del Arte 6: 13-36.

Mulvany, Eleonora. 2004. «Motivos de flores en keros coloniales: imagen y significado». Chungará 36 (2): 407-419.

Narozky, Tito y Darío Yzurieta. 2010. Aves de Argentina y Uruguay: guía de identificación. $16^{\mathrm{a}}$ edición. Buenos Aires: Vázquez Mazzini Editores.

Ramos Gómez, Luis. 2006. «Las vasijas de madera ornamentadas con laca utilizadas por los dirigentes andinos de la época Colonial: función y tipología de sus formas». Revista Española de Antropología Americana 36 (1): 83-117.

Rowe, John. 1961. «The Chronology of Inca Wooden Cups», en Essays in Precolumbian Art and Archaeology, Samuel Lothrop y Jay Kislak, eds., pp. 317-341. Boston: Harvard University Press. 
Van Kessel, Juan y Dionisio Condori Cruz. 1992. Criar la vida: trabajo y tecnología en el mundo andino. Santiago de Chile: Vivarium.

Vargas, Cesar. 1947. «Algunas fitomorfías raras o críticas de los antiguos peruanos». Boletín de la Sociedad Argentina de Botánica 2 (1): 39-42.

Yacovleff, Eugenio y Fortunato L. Herrera. 1935. «El mundo vegetal de los antiguos peruanos». Extracto de la Revista del Museo Nacional de Lima III (2): 243-322 (1934); IV (1): 31-103 (1935).

Ziółkowski, Mariusz S. 2000. «Los keros del Museo estatal de etnografía de Varsovia», en Iconografía de los keros, Oriana Wichrowska y Mariusz S. Ziółkowski, eds., pp. 121139. Varsovia: Misión Arqueológica Andina, Universidad de Varsovia.

. 2009. «Lo realista y lo abstracto: observaciones acerca del posible significado de algunos tocapus (t’uqapu) «figurativos». Estudios Latinoamericanos 29: 307-334. 